\title{
System Studies of DC Reactor Type Fault Current Limiter in Distribution Grid
}

\author{
M. Firouzi ${ }^{1}$, M. Pishvaie ${ }^{1,}$ G.B.Gharehpetian ${ }^{2}$ and F. Razavi ${ }^{1}$ \\ ${ }^{1}$ Department of Electrical Engineering,University of Tafresh,Tafresh,Iran \\ e-mail:mfa652@gmail.com, Mojtabapishvaei@Yahoo.com, razavi.farzad@taut.ac.ir \\ 2 Department of Electrical Engineering, Amirkabir University of Technology,Tehran,Iran \\ Phone/Fax number: +98 21640 6469, e-mail: grptian@aut.ac.ir
}

\begin{abstract}
A DC reactor type fault current limiter (FCL) in series with a downstream circuit breaker can be a solution to control fault current levels in electrical distribution systems. In order to integrate the DC reactor type FCL in to power grid, the performance of the DC reactor FCL should be studied. In this paper, short circuit analysis, based on the electromagnetic transient program (EMTP), has been used to investigate the behavior of the DC reactor type FCL installed in an electrical distribution grid. System studies show that the DC reactor type FCL can not only limit the fault current to an acceptable value, but also can mitigate the voltage sag. The Transient Recovery Voltage (TRV) could be damped in the presence of the DC reactor type FCL during fault clearing period, too.
\end{abstract}

\section{Key words}

DC reactor type Fault Current Limiter, Voltage sag, Transient Recovery Voltage (TRV)

\section{Introduction}

The growth of the generation of electrical energy and the increased interconnection of networks lead to higher fault current levels. Especially, the continues growth in the generation of electrical energy has the consequence that networks approach or even exceed their short circuit capability limits. The short circuit current will impose high dynamical and thermal stresses on electrical equipments. All equipments have to have a short circuit rating capable of withstanding this level. Traditionally, handling these increasing fault currents often requires the costly replacement of substation equipments or the imposition of changes in the configuration that may lead to decreased operational flexibility and lower reliability. An alternative approach to reduce the fault current is the application of Fault Current Limiters (FCLs). Their application allows equipments to remain in service, even if the fault current exceeds its rated peak and short-time withstand current. In case of newly planned networks, fault current limiters allow the use of equipment with lower ratings which renders possible considerable cost savings[1]-[3]. To reduce the short circuit current, the superconducting fault current (SFCL) is expected to be introduced in real power system [4]. The application of the SFCL would not only decrease the stress on device but also offer a reliable interconnection to secure the network. This is very effective means to the system stability and power quality in terms of availability and voltage drop, which is real need today. There are various type of SFCLs which are based on different superconducting material and designs such as, flux lock, transformer, resistive, DC reactor types and so on[9]. In this paper, a DC reactor type FCL has been studied. It has zero impedance under the normal condition and large inductive impedance under the fault condition. Its advantage is that it can limit fault current without delay and no damage because it doesn't undergo $\mathrm{S} / \mathrm{N}$ transition of superconductor [5-7]. The waveform of the fault current does not have a surge current in the case of application, because DC reactor prevents a sudden increasing of current. Therefore, the fault current gradually increases during the fault [8-9]. Distribution systems have been designed and built as a passive unidirectional system to accept generation or bulk supplies from transmission grids or substations. Most of distribution structures are radial. The short circuit current is just limited by the impedance of various system components. Thus, the integration of the SFCL could offer an effective solution to controlling fault current levels in distribution grids. To achieve a successful interruption of circuit breaker, not only on interrupting current but also on Transient Recovery Voltage (TRV) appearing across the breaker contacts must be considered. In other words, depending upon the kind of the fault current and its and system's parameters, the insertion of the fault current limiter in to the power system can result in more severe interrupting problems. 
Therefore, it is important to study the interrupting behavior of circuit breakers in the presence of the fault current limiter [10-12].

\section{Three-Phase DC Reactor Type FCL}

Fig. 1 shows the three-phase DC reactor type FCL, which consists of the superconducting coil (SC), series transformer bridge circuit. The diode bridge converts three-phase AC to DC current, which flows through the super- conducting coil. The current through the primary and secondary winding of transformer are defined as Ip, Is, respectively, and the ratio of transformer is $\mathrm{N}$, as follows:

$$
\frac{I_{P}}{I_{S}}=\frac{1}{N}
$$

The DC reactor current $(I s c)$ through the superconducting coil is almost equal to the peak value of the secondary current.

$$
I_{S C}=\sqrt{2} I_{S}=\sqrt{2} N I_{P}
$$

After charging the SC and in the steady state condition, the current of SC is approximately constant, so $d I s c / d t$ is equal to zero and the impedance seen by the primary side of the coupling transformer is very low. Under the fault conditions, the current increases with a constant rate. The per-phase current is approximately given by the following equation [5].

$$
I_{p h}=\frac{V_{m}}{L}\left(1+I_{0}\right)\left(t-t_{f}\right) \cos \left(2 \pi f_{1} t+\varphi\right) \quad t \geq t_{f}
$$

Where $V_{m}$ is the magnitude of the source voltage, $L$ is the inductance of the superconducting coil (referred to the primary side), $t_{f}$ is the fault starting instant, $\varphi$ is the phase angle, $f_{l}$ is the fundamental frequency and $I_{0}$ is the magnitude of the operating current under normal conditions.

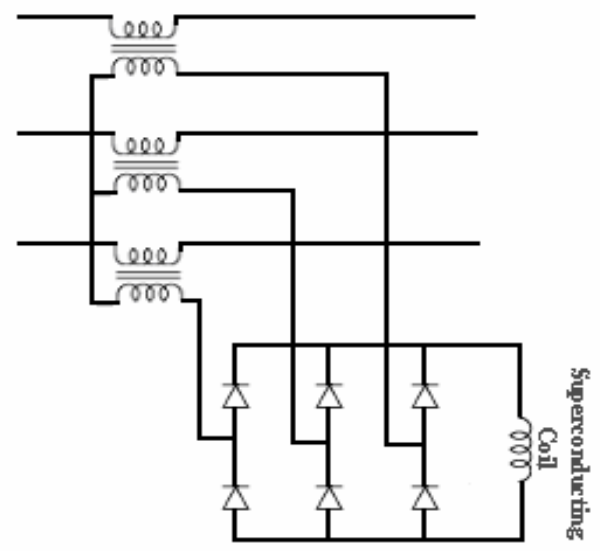

Fig. 1. DC reactor type SFCL schematic diagram

\section{DC Reactor Type FCL In Distribution System}

Most of the distribution systems have radial form. As a result in any branch of a radial system, power only flows in one direction. The distribution voltage levels are in the range of $10 \mathrm{kV}$ to $30 \mathrm{kV}$. The systems have continuous current ratings less than or equal to $600 \mathrm{~A}$ and fault current ratings less than $20 \mathrm{kA}$ [4]. It can be expected that there will be interactions between the DC reactor type FCL and power system, if FCL is placed in the grid. A typical distribution system is represented in Fig. 2. The source impedance includes the transformer impedance and the upstream short-circuit impedance. Parallel feeders are connected to the Point of Common Coupling (PCC). The bus is supplied by a substation transformer from an $110 \mathrm{kV}$ network. The upstream source system is modeled as an infinite bus and the source impedance consists of an equivalent resistance and inductance connected to the local distribution substation. The feeder consists of cables, FCL and a circuit breaker. The cable can be modeled as a $\pi$-circuit with inductance and capacitance per unit length. The load is modeled as an lumped series R-L-C branch with a power factor of 0.886. A fault simulation switch at the load side, as shown in Fig.2, should model a three phase to ground short-circuit. After three cycles, the circuit breaker opened to clear the fault. The circuit breaker is modeled as an ideal time-controlled switch with a parallel capacitance. This capacitance is the total capacitance of the source side circuit, which includes the stray capacitance of circuit breaker to the ground. The simulation has been carried out with a fault starting at $\mathrm{t}=100 \mathrm{~ms}$. The circuit breaker has been opened after 3 cycles. (Distribution level circuit breakers typically open in two cycles after receiving the opening order. Considering one cycle delay, the fastest expected opening time can be three cycles).

The total simulation time was $200 \mathrm{~ms}$ according to the circuit breaker opening time, and the simulation step is $1 \mu \mathrm{s}$. The operation current magnitude during normal condition is $300 \mathrm{~A}$. The parameters for the simulation have been listed in table 1 .

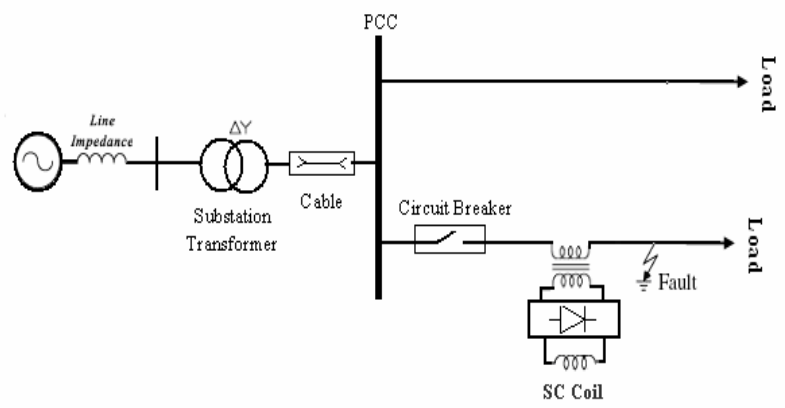

Fig. 2. Schematic diagram of study system 
TABLE I.

SYSTEM PARAMETER

\begin{tabular}{|c|c|}
\hline PARAMETER & VALUE \\
\hline Supply & $110 \mathrm{KV}, 50 \mathrm{~Hz}$ \\
\hline Stepdown transformer & $110 / 15 \mathrm{KV}, 10 \mathrm{MVA}$ \\
\hline Inductance of SC & $200 \mathrm{mH}$ \\
\hline Load & $5 \mathrm{KW}, \mathrm{PF}=.88$ \\
\hline
\end{tabular}

\section{Simulation Results}

\section{A. Fault Current Limitation}

In the first case, a symmetrical downstream fault has been simulated. Fig.3 shows the line current with and without FCL application. It is obvious in Fig.3-a that the downstream fault current is very high, which can damage

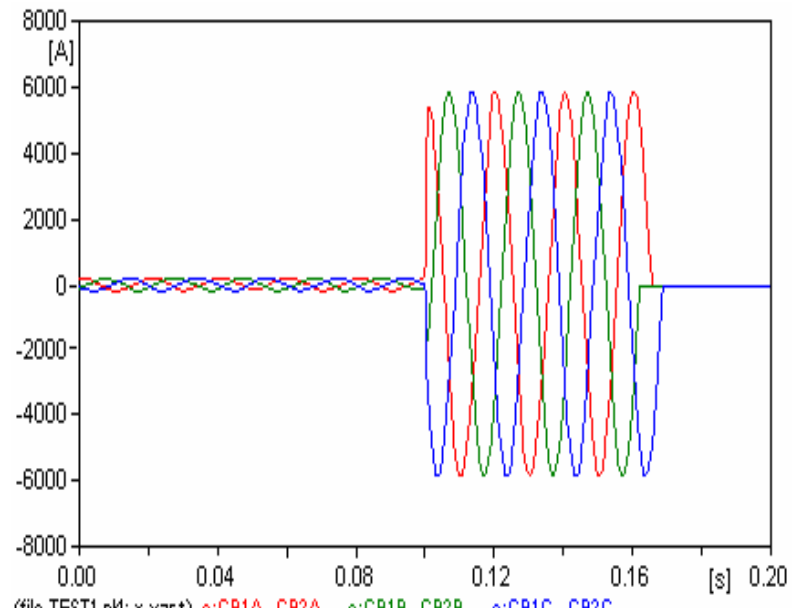

(a)

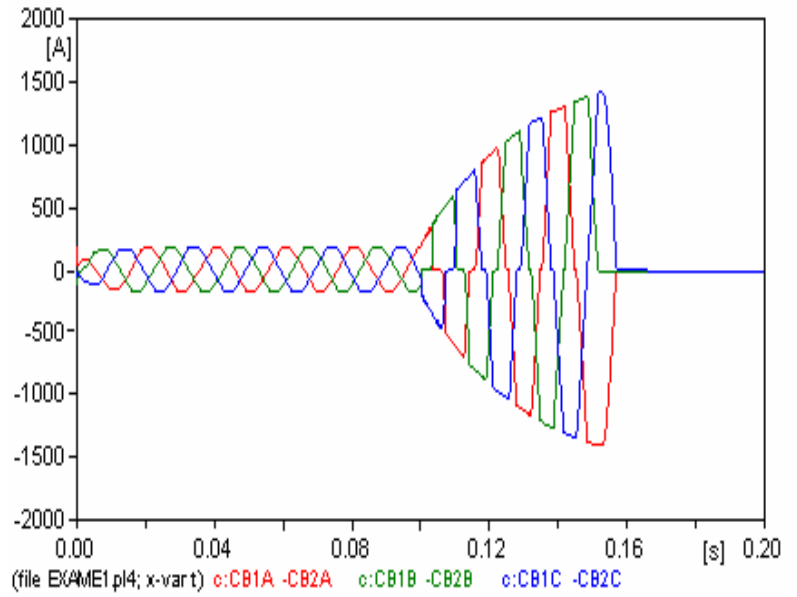

(b)

Fig 3: Fault current a-without FCL and b-with FCL

the system devices. It should be said that source and line impedance is so low that they cannot limit the fault current. It can be seen in Fig.3-b that the fault current has been limited to $1.5 \mathrm{kA}$ in that case of FCL application. It is obvious that the increase of fault current can be limited by the inductance of SC without any delay and the fault current increases gradually with a constant rate during fault period.

\section{B. Mitigation of Voltage Sag}

Fig. 4 shows the 3-phase to ground voltages of PCC. In the Fig.4-a, voltage drops sharply to $30 \%$ of the normal voltage after the short circuit, so called voltage collapse. The voltage needs nearly one cycle to be recovered to its normal value with a transient over voltage. The DC reactor type FCL, has been modeled and the simulation results have been presented in Fig.4-b. The voltage sag has been improved effectively.

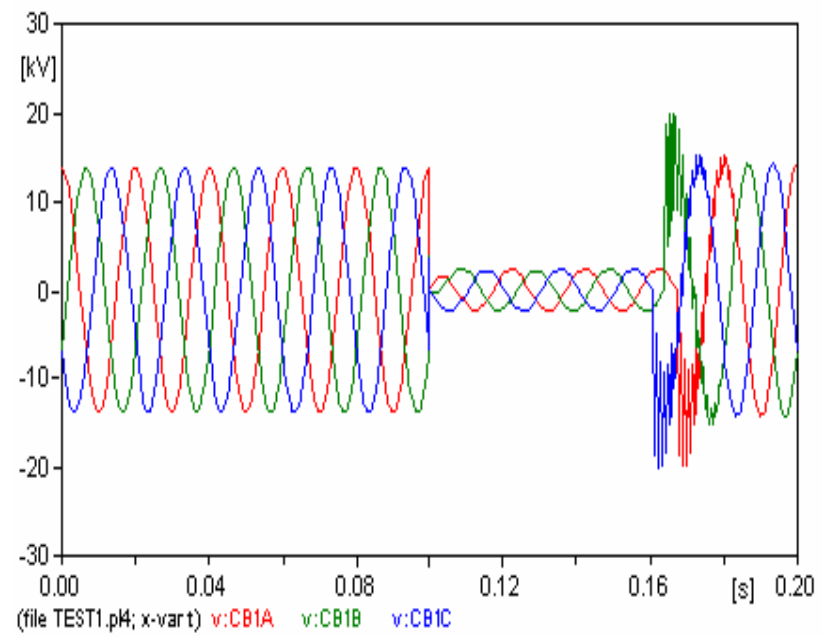

(a)

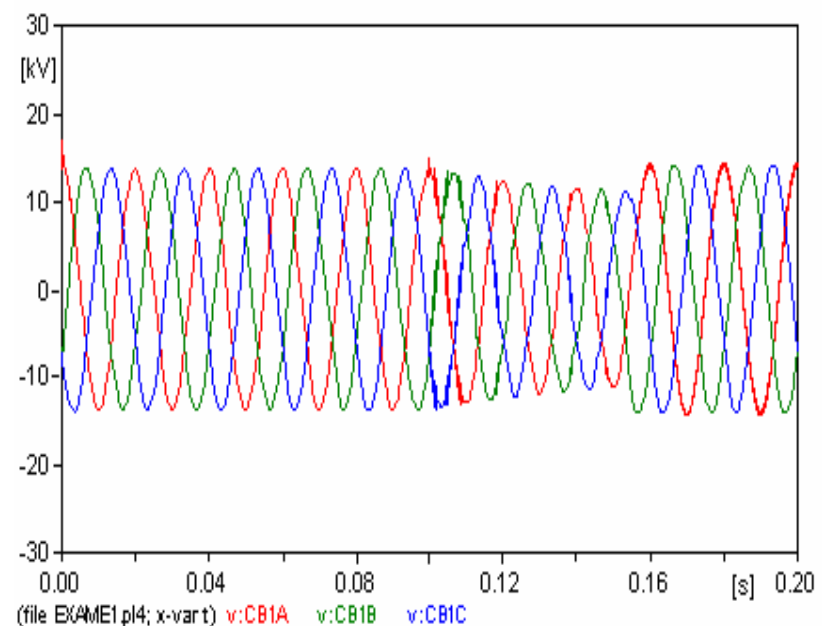

(b)

Fig 4: Voltage of PCC a-without FCL and b-with FCL

\section{Circuit Breaker Transient Recovery Voltage}

A DC reactor type FCL can absorb the energy from the grid during the fault condition and it acts like a variable resistance which is installed in series with a circuit breaker. When the circuit breaker attempts to interrupt the limited fault current, an over voltage is developed across contacts [6]. This voltage is called Transient Recovery Voltage (TRV) of the circuit breaker. 
Circuit breakers may fail to interrupt fault currents when power systems have transient recovery voltage levels, which exceed the rating of circuit breakers. The Rate of Rise of Recovery Voltage (RRRV) is an important parameter in the power system operation, presented in IEEE C37.41 standard. Fig. 5 shows the circuit breaker's TRV with and without installation of FCL. Fig. 6 is an enlargement of Fig. 5-a. The value of the RRRV is about $36 \mathrm{~V} / \mu \mathrm{s}$, if there is no SFCL. As it can be seen in Fig.5-b, in the case of DC reactor type FCL installation, the circuit breaker's TRV is damped and its value is about $5 \mathrm{~V} / \mu \mathrm{s}$.

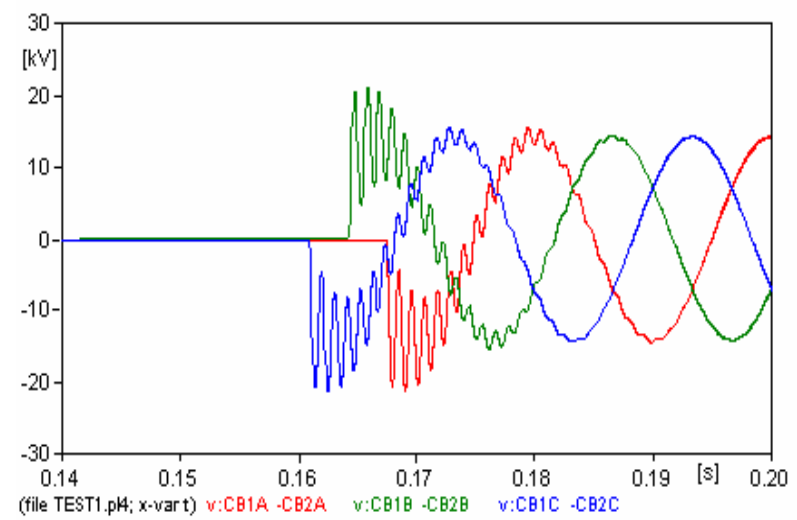

(a)

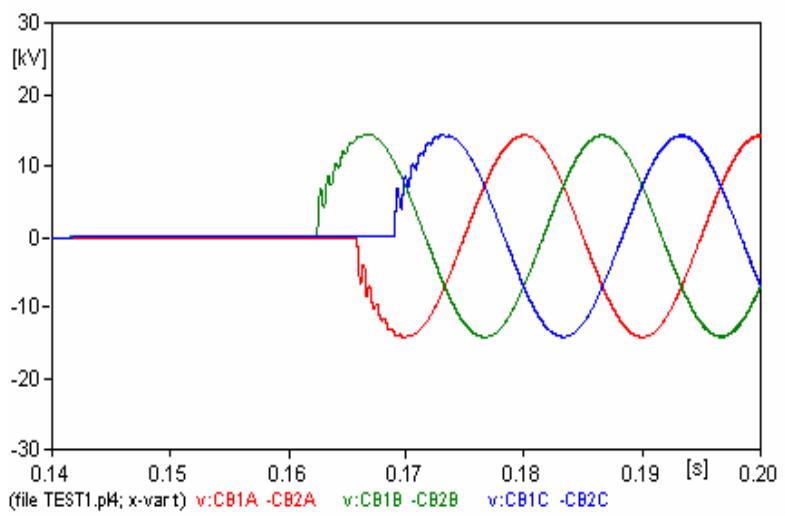

(b)

Fig .5: Circuit breaker TRV a-without FCL and b-with FCL

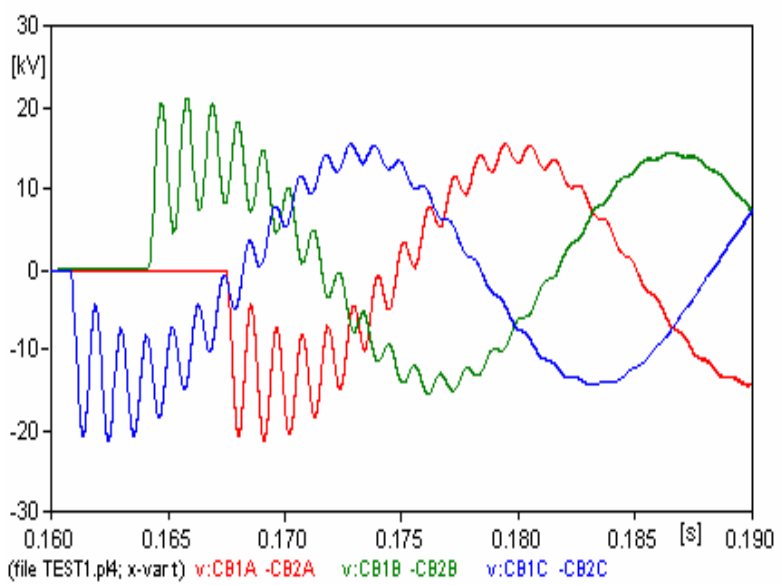

Fig 6. Enlargement of Fig.5-a

\section{Conclusion}

In this paper, it is shown that a DC reactor type can limit the fault current, can mitigate the voltage sag and can reduce the TRV and RRRV of circuit breaker. These results have been obtained based on EMTP simulation.

\section{References}

[1] Hector G.Sarmiento, R.Pampin, "An Example in Controlling Short Circuit Levels in Large Metropolitan Area," Power Egineering Societey General Meeting, IEEE, Vol.2, June 2003

[2] CIGRE WG A3.10: "Fault Current Limiters in High Electrical Medium and Voltage Systems", CIGRE Technical Brochure, No. 239, 2003.

[3] CIGRE WG A3.10, "Fault Current Limiters Report on the Activities of CIGRE WG 3.16,"CIGRE Technical Brochure, 2006

[4] P. G. Slade et al., "The Utility Requirements for a Distribution Fault Current Limiters," IEEE Trans. Power Delivery, vol. 7 , no. 2, pp. 507-515, April 1992.

[5] Minseok.Joo., "Harmonic Control of Inductive Superconducting Fault Current Limiter System with DC Reactor," IEEE Transaction on Applied Superconductivity, vol. 14, no. 2, June 2004

[6] E Ro Lee, S. Lee, Ch. Lee, H.Jun Suh, "Test of DC Reactor Type Fault Current Limiter Using SMES Magnet for Optimal Design," IEEE Trans. Appl. supercond., vol.12, no. 2, March 2002

[7] T. Hoshino, K. M. Salim, M. Nishikawa, I. Nuta, and T. Nakamura,"DC Reactor Effect on Bridge Type Superconducting Fault Current Limiter During Load Increasing," IEEE Trans. on Appl. Supercond., vol. 11, no.1, pp. 1944-1947, March 2001

[8] M. Yamaguchi, S. Fukui, T. Satoh, Y. Kaburaki, T. Horikawa, and T.Honjo, "Performance of DC Reactor Type Fault Current Limiter Using High Temperature Superconducting Coil," IEEE Trans. Appl. Supercond., vol.9, no. 2, pp. 940-943, 1999.

[9] T.Nomura, M. Yamaguchi, S. Fukui, K. Yokoyama, T. Satoh, and K. Usui, "Single DC Reactor Type Fault Current Limiter for $6.6 \mathrm{kV}$ Power System," IEEE Trans. Appl. Superconduct., vol. 11, no. 1, pp.2090-2093, Mar. 2001

[10] E.Calixte, Y.Yokomizu, T.Matsumura and H.Fujita, "Reduction in Severity of Circuit Breaker Duty Under Generator-Fed Fault Condition by Means of Resistive Fault Current Limiter," International Journal of Power Energy System, Power Con Special Issue 2004, pp.24-31

[11] E.Calixte, Y.Yokomizu, T.Matsumura and H.Fujita "Reduction of Rating Required for Circuit Breakers by Employing Series-Connected Fault Current Limiter,"Generation, Transmission and Distributin IEE Proceedings, pp.36-42, Jan 2004

[12] E.Calixte, Y.Yokomizu and T.Matsumura "Theoretical Evaluation of Limiting Resistance Required for Successful Interruption in Circuit Breaker with Fault Current Limiter,"pp.317-322 IEEE, Oct. 2005 